\title{
Effects of Augmented Reality Glasses on the Cognitive Load of Different Age Groups
}

\author{
Yagmur Dila IKIZ ${ }^{1}$, Hilal ATICI-ULUSU ${ }^{1}$, Ozlem TASKAPILIOGLU ${ }^{2}$, Tulin GUNDUZ ${ }^{3}$ \\ ${ }^{1}$ Industrial Engineering Program, Graduate School of Natural and Applied Sciences, Uludag \\ University, Bursa, Turkey \\ ${ }^{2}$ Department of Neurology, Medical Faculty, Acibadem University, Istanbul, Turkey \\ ${ }^{3}$ Department of Industrial Engineering, Faculty of Engineering, Uludag University, Bursa, Turkey
}

\begin{abstract}
.
With the advancement of technology, augmented reality glasses have been started to using in all areas. With augmented reality glasses, users can reach their wishes more easily and comfortably in different sectors such as education, entertainment, construction and automotive. However, it is not known how these glasses create a cognitive load on the user. In this article, the effect of augmented reality glasses to be used on an assembly line of an automotive company on the cognitive load was investigated. EEG, which detects fine fluctuations in instant load, was used for the measurement of cognitive load. The study was carried out with 4 participants ( 2 Female - 2 Male) and analyzed according to the difference between the ages ( 35 above and below). There was no difference between the participants under the age of 35 and above the age of 35 years. Therefore, it is seen that over 35 years old people will not have extra cognitive load in using the augmented reality glasses.
\end{abstract}

Keywords. Augmented Reality Glasses; Cognitive Load; Electroencephalography; Automotive Industry;

\section{Introduction}

Augmented reality is a diversity of virtual environments (VE) or mostly known as virtual reality [1]. Augmented reality (AR) is the technology which computer graphics technique in the real world of virtual symbols. The first functional AR technology was originated in 1990's and used at the U.S. Military in 1992 [2]. After that AR entered commercial areas like gaming and entertainment and now using by all other industries.

One of these industries is the automotive manufacturing sector. Research in augmented reality technology has also expanded and strengthened in the automotive manufacturing industry [3]. However, it is still not known how the use of this technology creates a cognitive load on human beings.

Cognitive load is the load brought into the working memory of cognitive processes that can be measured at different levels [4]. In simple words, the amount of load generated by the working memory at the time a task is performed [5].

Continuous alertness is required in the work environment against multiple flows of information in the brain. This flow creates cognitive workload in the brain. In addition to 
the harsh working conditions in the automotive industry, the effect of using augmented reality glasses on cognitive load needs to be clarified.

There are many different techniques in cognitive load measurement. Among these techniques, the use of EEG to measure cognitive load functions in the brain is also used. EEG is a brain imaging technique that measures electrical activity in the brain through electrodes placed on the scalp [4]. At the same time, the EEG will ensure a good match between the participant's ability and the performance of the system. The demand brought by the operator to the limited mental resources will be understood by the temporal data of the EEG [6].

Cognitive load of the operators wearing augmented reality glasses was measured and analyzed with EEG. According to these analyzes, a comparison is made between the age status of the participants (below 35 and above 35).

\section{Method}

\section{1 Participants}

The study included 4 people, 2 female and 2 male, who had no general health status, no disease and drug use, and volunteered for the study. Each participant signed a volunteer form, as required by the Uludag University Faculty of Medicine Clinical Research Ethics Committee. Participants were asked not to have alcohol and caffeine taken 24 hours before the experiment. Before the experiments The Hamilton Depression Assessment [7] and Hamilton Anxiety Assessment [8] questionnaires were applied to the participants.

\subsection{Procedures}

The experiments were carried out in the real environment in the assembly line of an automotive company. Participants were selected from the assembly line of the company and then divided into two groups according to their gender and the experiments were performed first with the male and then with the female group. Procedure was to take the pieces they read from the work order papers in their hand and put them into the transport vehicle. In the experiment, this process is done with augmented reality glasses. The participant went to the boxes according to the part number on the screen of the augmented reality glasses and loaded the piece into the vehicle by reading the square code in front of the boxes. Sony SmartEyeglass was used in the project.

\subsection{EEG Recording}

The EEG recording was performed with the Brain Products Company's EASYCAP product and Analyzer 2 software. The cap has Bluetooth feature and the records were taken without limiting the movement. The cap also has 24 channels. The impedances were reduced below $10 \mathrm{k} \Omega$.

Five different EEG measurements were performed for each participant, including 3 replicates. The first measurement was taken without glasses, the participant read the part numbers from the paper and the other 4 measurements were taken with glasses (Fig. 1). 


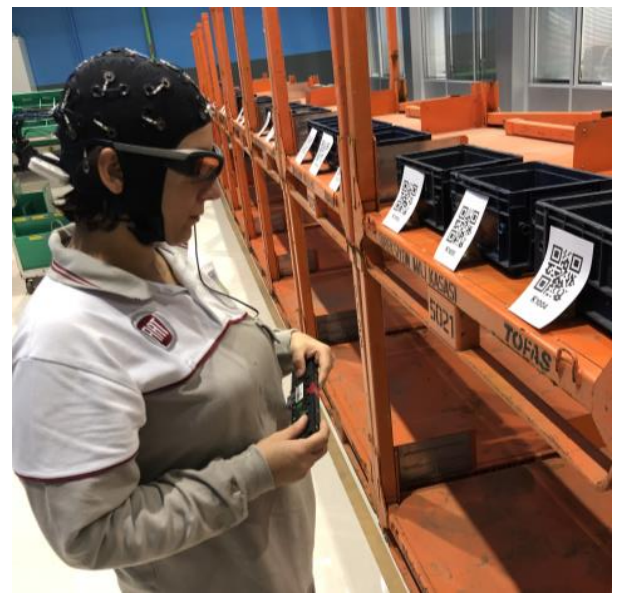

Fig. 1. An example of an experimental study

\subsection{Analysis}

In the EEG analysis, $\mathrm{Fp}_{1}, \mathrm{Fp}_{2}, \mathrm{~F}_{3}, \mathrm{~F}_{4}, \mathrm{~F}_{7}, \mathrm{~F}_{8}, \mathrm{O}_{1}, \mathrm{O}_{2}, \mathrm{~T}_{7}, \mathrm{~T}_{8}$ channels were used for cognitive load measurement. Firstly, the data were subjected to filtering. This filtering was performed according to the beta and gamma waves to be used in the analysis. Data were cleared of line noise and motion artefacts. Comparisons were made by looking at the area under the graph of clean data.

It is known that the more the amplitude of P300 used in cognitive load comparisons increases, the more the cognitive load decreases [9]. From this point of view, it was assumed that the cognitive load is lower in the measurements where the area value is higher.

\section{Results and Conclusions}

Area values under the graphs were calculated by Analyzer. These areas were given in Tab. 1 in terms of $\mu \mathrm{V} *$ ms. EEG activity of some experiments is shown in Fig. 2 as a head view.

Tab. 1. Area values for experiments

\begin{tabular}{|c|c|c|c|c|c|c|c|c|c|}
\hline \multirow{2}{*}{\multicolumn{2}{|c|}{$\frac{\text { Experiment }}{\text { Participant }}$}} & \multicolumn{4}{|c|}{ Experiments without glasses } & \multicolumn{4}{|c|}{ Experiments with glasses } \\
\hline & & 1 & 2 & 3 & 4 & 1 & 2 & 3 & 4 \\
\hline \multirow{4}{*}{ 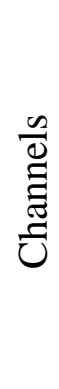 } & $\mathrm{Fp}_{1}$ & 1.493 & 1,748 & 18,895 & 5.624 & & 14.602 & 17.847 & 9.483 \\
\hline & $\mathrm{Fp}_{2}$ & 1.596 & 0,424 & 15,379 & $\begin{array}{c}- \\
4.045\end{array}$ & $\begin{array}{c}- \\
17.959\end{array}$ & -9.972 & $\begin{array}{c}- \\
29.815\end{array}$ & 6.433 \\
\hline & $\mathrm{F}_{3}$ & 2.392 & $\begin{array}{l}- \\
1,190\end{array}$ & 3,623 & $\begin{array}{c}- \\
4.189\end{array}$ & -9.115 & -5.387 & $\begin{array}{c}- \\
29.500\end{array}$ & 4.905 \\
\hline & $\mathrm{F}_{4}$ & 2.296 & $\begin{array}{c}- \\
1,645\end{array}$ & $-2,676$ & $\begin{array}{c}- \\
3.897\end{array}$ & -3.085 & 11.604 & $\begin{array}{c}- \\
35.813\end{array}$ & -1.596 \\
\hline
\end{tabular}




\begin{tabular}{|c|c|c|c|c|c|c|c|c|}
\hline $\mathrm{O}_{1}$ & 2.397 & $\begin{array}{c}- \\
0,343\end{array}$ & 6,392 & 5. & $\begin{array}{c}- \\
23.473\end{array}$ & $\begin{array}{c}- \\
18.662\end{array}$ & $\begin{array}{c}- \\
92.130\end{array}$ & $\begin{array}{c}- \\
17.270\end{array}$ \\
\hline $\mathrm{O}_{2}$ & 3.433 & $\begin{array}{c}- \\
0,817\end{array}$ & 3,249 & $\begin{array}{c}- \\
3.490\end{array}$ & $\begin{array}{c}- \\
26.913\end{array}$ & $\begin{array}{c}- \\
39.794\end{array}$ & $\begin{array}{c}- \\
51.830\end{array}$ & $\begin{array}{c}- \\
37.089\end{array}$ \\
\hline $\mathrm{F}_{7}$ & 2.427 & $\begin{array}{c}- \\
2,525\end{array}$ & 4,015 & $\begin{array}{c}- \\
3.626 \\
\end{array}$ & -2.282 & $\begin{array}{c}- \\
14.581 \\
\end{array}$ & $\begin{array}{c}- \\
27.801 \\
\end{array}$ & 7.423 \\
\hline $\mathrm{F}_{8}$ & 2.212 & $\begin{array}{c}- \\
1,169\end{array}$ & $-13,497$ & $\begin{array}{c}- \\
3.483\end{array}$ & $\begin{array}{c}- \\
13.694 \\
\end{array}$ & -4.529 & $\begin{array}{c}- \\
38.546 \\
\end{array}$ & -4.812 \\
\hline $\mathrm{T}_{7}$ & 4.858 & 2,177 & 1,742 & $\begin{array}{c}- \\
9.626\end{array}$ & 11.218 & $\begin{array}{c}- \\
10.729\end{array}$ & $\begin{array}{c}- \\
27.186\end{array}$ & -3.219 \\
\hline $\mathrm{T}_{8}$ & 2.548 & 3,237 & 49,031 & $\begin{array}{c}- \\
6.753\end{array}$ & 4.036 & $\begin{array}{c}- \\
15.484\end{array}$ & -4.005 & $\begin{array}{c}- \\
19.975\end{array}$ \\
\hline
\end{tabular}

*Participants 1 and 2 are under age 35 and participants 3 and 4 are over age 35 .

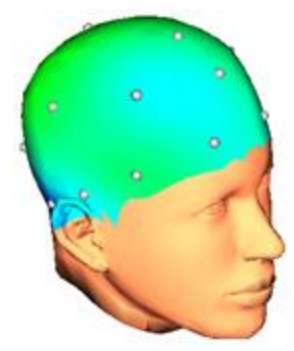

(a)

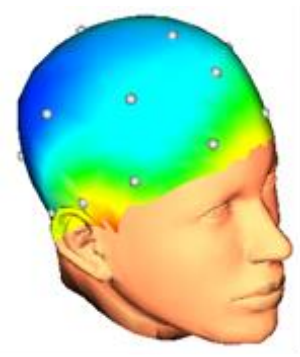

(b)

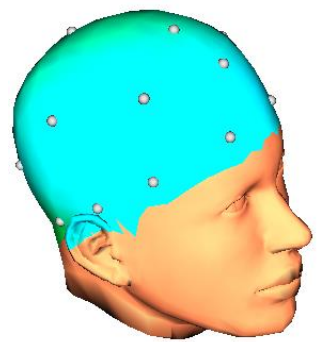

(c)

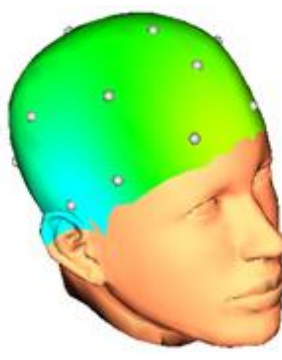

(d)

Fig. 2. (a) Participant 1 without Glasses, (b) Participant 1 with Glasses, (c) Participant 2 Without Glasses, (d) Participant 2 With Glasses

When the absolute values of the areas were compared, it is seen that the cognitive load is low where the area value is high. When the area values of the participants under the age of 35 were examined, participants had less cognitive load in all of experiments with glasses. For the participants over the age of 35 years, it was observed that $80 \%$ less cognitive load in experiments with glasses than without glasses.

According to these results, there is no difference between the participants under 35 and over 35 years of age. In other words, participants over 35 years of age can use the augmented reality glasses on assembly line.

In this study, it was researched whether the use of augmented reality glasses in the assembly line of an automotive company would create additional cognitive load. According to the results of EEG measurements, it was seen that the participants had less cognitive load in the experiments with glasses. In addition, there were no differences for the different age groups. It was found that the use of augmented reality glasses in the assembly line would not bring any additional cognitive load for both age groups. 


\section{Acknowledgements}

This paper is an output of the TUBITAK project "An investigation of cognitive load effect of using augmented reality glasses in automotive manufacturing", project number 217M505. We thank Tofaş Turkish Automobile Factory Inc. for their contributions.

\section{References}

1. Azuma, R. T.: 'A survey of augmented reality', Presence: Teleoperators \& Virtual Environments, 6(4), 355-385, 1997

2. Rosenberg, L. B.: The Use of Virtual Fixtures as Perceptual Overlays to Enhance Operator Performance in Remote Environments, Stanford Univ Ca Center for Design Research, 1992

3. Nee, A. Y.: 'Augmented reality applications in design and manufacturing', CIRP annals, 61(2), 657-679, 2012

4. Antonenko, P.: 'Using electroencephalography to measure cognitive load', Educational Psychology Review, 22(4), 425-438, 2010

5. Das, D.: 'Unsupervised approach for measurement of cognitive load using EEG signals', 13th IEEE International Conference on BioInformatics and BioEngineering, 1-6, 2013

6. Kumar, N.: 'Measurement of cognitive load in HCI systems using EEG power spectrum: an experimental study', Procedia Computer Science, 84, 70-78, 2016

7. Hamilton, M.: 'A rating scale for depression', Journal of Neurology, Neurosurgery, and Psychiatry, 23, 56-62, 1960

8. Hamilton, M.: 'The assessment of anxiety states by rating', British Journal of Medical Psychology, 32, 50-55, 1959

9. García-Larrea, L.: 'P3, positive slow wave and working memory load: a study on the functional correlates of slow wave activity', Electroencephalography and Clinical Neurophysiology/Evoked Potentials Section, 108(3), 260-273, 1998 